\title{
Cronica Universitaria
}

\section{DIREITO E ORGANIZAÇÃO SOCIAL}

\author{
J. R. Vieira Neto \\ Professor Catedrático da Faculdade de \\ Direito da Universidade do Paraná \\ (Aula inaugural do curso jurídico \\ proferida em 10 de março de 1960)
}

\section{Eminente Diretor}

Professôres, Estudantes:

SEJA a primeira frase de Boas Vindas, e dirija-se aos Calouros desta Faculdade.

Estudante também e sempre alegra-me o coração rever - mais de trinta anos depois - nestas fisionomias de alegre pureza e cândida esperança - a minha própria; ver-me a espelhar-me na vossa mocidade e em vossos eternos ideais - Aquiles - redivivo em homéricos efêbos que só tendes de dissemelhança - a espada, a lança, o elmo, a couraça refulgentes - trazei-las na fôrça indômita do próprio pensamento.

Aqui, tendes os nossos votos de estímulo, a promessa fraternal de nossa solidariedade e de nosso devotamento: canção de amigo, pacto de companheiro no ajuste da jornada, - as vias exclusivas de nossos propósitos fundamentais: mestres, mesmo mais amigos e companheiros do que mestres, vo- tamos o vosso proveito, apostamos no vosso progresso e na vossa meta - no trabalho conjunto, em colaboração honesta, - expontâneos, duradouros, - em todos os anos dêste lustro que, juntos, iremos percorrer.

Destina-se esta aula inaugural - marco de tradição na reabertura dos cursos jurídicos - de indistinto a todos os seus alunos e, por isso, escolhi como propósito, um tema que a todos possa servir e interessar.

Aos calouros, um preâmbulo singelo e necessário à compreensão do papel e das funções do direito privado, dentro de uma estrutura de sociedade humana, em qualquer momento de sua vida histórica; aos veteranos, a ponderação dialética em tôrno do que já sabem de direito positivo, - com o sentido amenizante e relativista em relação àqueles princípios dogmáticos que são tomados e erigidos no co- 
mum, como eternas instituições e indestrutíveis edifícios da ciência jurídica.

Um período histórico que foi relativamente curto (neste País de recuperações formidáveis) mas de profundas e nefastas influências, encarregou-se de oferecer e divulgar ao povo desprevenido, o fetichismo da lei, a perversão de subserviência à norma revelada e imposta de cima, como suprema conquista da Ordem, e a função estabilizadora de instituições ultrapassadas - e, ao solo e côro dessa repetição sistemática e, assim, convincente, juntara-se de uso quotidiano e mais convincente, o contraponto da aplicação policial da lei, com os argumentos insuperáveis da borracha, do espancamento $\mathrm{e}_{\mathrm{c}} \mathrm{da}$ tortura.

Tôda uma geração educada nesse período, com as mais honrosas e parcas exceções, caracterizou-se pelo conformismo apático de entes e mentes condicionados, à maneira da utopia de HUXLEY, a trazer como elemento de tragédia, o falso senso de humor mal atribuído à amorável personagem de SHAKESPEARE:

Ó maravilha! Admirável mundo novo, que produz criaturas como essas...

Alegro-me hoje ao reconhecer e proclamar que, menos de três lustros, em nossa recuperação democrática, formaram esta geração que nos enche de orgulho - pois que, ao menos, é ciosa de sua liberdade mental que não foi embalada pela hipnose de slogans de propaganda dirigida, proibindo-lhe a humana função do pensamento; geração de alto senso crítico que atinge e derriba das peanhas mal seguras - bonzos, tabus, ídolos de pés de barro, - mocidade ao menos consciente - e, porisso, melhor.

Digo ao menos, pois que é lenta e progressiva essa recuperação, perdidas algumas gerações de moços para a vida pública - ineficazes, d e s o nest a s, desfibradas, mortas sem saber - e de que remanescem lamentáveis exemplos na administração, no remanso panúrgico dos legislativos, nos fracassos inexplicáveis da justiça...

Digo ao menos, porque ainda vejo nos olhos, no sorriso cético desta nova geração de moços - sorriso que não gosto de ver, nem mesmo na fisionomia cansada dos velhos - a descrença pelo fracasso das instituições, um amargo e acerbo desencanto que não vem acompanhado de carteza dinâmica e criadora - de que, a essas instituições, é lícito e possível (e carregais o dever dessa tarefa) - reformá-las, modificá-las, atualizálas - tornando a lei um instrumento de honestidade e de progresso, afastando os indignos da vida pública, conformar as instituições às tendências construtivas de um Povo, poder dizer então, agora sem ironia, no mais literal de seu sentido puro, à maneira exaltada da juventude de uma eterna Miranda:

ó maravilha!...

Admirável mundo novo

Que produz criaturas como es-

sas!

Conta Rui, o divino Rui, em sua Oração aos Moços, o diálogo que XENOFONTE registrara, entre Péricles e Alcebíades, a respeito da 
lei e da obediência que lhe devem os probos cidadãos. Dizia Péricles que a lei é a expressão da vontade do povo, determinada para o bem. Mas, ponderava Alcebíades, si a lei fôsse oriunda dos desígnios de uma oligarquia, de um número diminuto de homens, ainda se lhe devia respeito? Sem dúvida, dizia o moço. Porém, insistia o velho, si a lei vem de um tirano, si ocorrem violências, si a ilegalidade se pratica, si o poderoso deprime o fraco, cumpre ainda obedecer? Péricles hesita, mas aceita. Sim, creio que sim. Todavia, redargue Alcebíades, si o tirano constrange os cidadãos a lhe acatarem os caprichos, não será êle o inimigo das leis? Péricles admite que errara, chamando lei às ordens de um tirano. No entanto, retruca o Velho, si poucos cidadãos impõem sua vontade à tôda a multidão, não será isso violência? Péricles, vacilando, confessa que sim. Com tal aceitação, Alcebíades triunfa: E si a multidão governa e impõe a uns poucos a sua vontade, não será, também isso, violência? Péricles não acha o que dizer...

Não é nesta forma simplista que vos quero falar das leis regentes das relações privadas, de uma estrutura política que retrata uma organização social.

Disse um moderno pensador e extraordinário dirigente que não tinha peias, nem preconceitos, que, possivelmente, não existe problema tão complexo, embaraçado, e enganoso - embrulhado pelos ideólogos e filósofos, pela jurisprudência, a sociologia, os interêsses da classe que domina - quanto êsse problema do Estado e do Direito codificado.

No princípio era simples.

Sem dúvida a horda não tinha leis, mas a presença do perigo comum sempre ditou a unidade dos mais fracos. A colaboração é transitória, pelos desentendimentos da partilha. A caça pressupõe a posse ou utilidade do instrumento de ataque, as primícias e despojos muito antes da noção de propriedade. Não se pode conceber a família em tôrno da mãe, tal como nas sociedades animais, com os mesmos princípios, costumes e regras que, hoje, alguns supõem eternas, imutáveis... De direito sucessório não se cogita que não há no que suceder. O morto não tem nem perde, disse com muita graça o $\mathrm{Sr}$. PONTES DE MIRANDA. Não se trata de suceder mas de ocupar a coisa derelita, abandonada.

O casamento não supõe um Código; tôdas as espécies que se perpetuaram, evoluiram, transformaram, de certo prescindiram de um conjugo vobis, salvo as vistas complacentes da Demeter Acaia, a poderosa e fecunda Natureza... De contrato civil ainda não se trata, porque a troca, a locação irão mais tarde pressupor o princípio, ainda ausente, da especialização e da divisão do trabalho.

Desenvolvendo-se a sociedade primitiva em tôrno da família nos vários estágios de sua transformação, em que o elemento de ligação comunal é o laço de sangue, - ainda êsse princípio vai comandar ulteriores complexos sociais que do grupo sindiásmico se dirigem à monogamia. Si a gens é ainda um grupo sangüíneo, é natural e lógico deduzir o caráter 
imediato das regras de convivência, as normas públicas de coerção.

De comêço todo o direito é público. A obediência familiar passa ao chefe, o expediente do talião impede a restauração da ordem pelo particular, quando a sociedade o assume, para evitar a perpetuação da luta, perturbadora da ordem, até da integridade potencial do grupo. O terror primitivo em busca de explicação e proteção impõe a divindade, - e esta há de homologar o princípio de autoridade; o chefe é juiz e sacerdote. Tudo isto pressupõe, há muito, a modificação das relações de produção econômica: a busca de melhores pastagens tornou possível em seu caráter errante, a coesão permanente do grupo; a agricultura fixou-o. O aldeamento erige a cidade. Si a regra é função da convivência, e feita por quem tem interêsse nela e fôrça de impô-lo à observância, é óbvia a derivação do seu caráter da autoridade do que é sagrado e do interêsse das famílias dominantes.

ARISTÓTELES confessava que as leis tendem a proteger os "ótimos ou melhores" isto é, alguns cidadãos proeminentes da Cidade, pelos quais esta é regida e porisso se denominam principais... É fácil depreender que o interêsse público da polis confunde-se com o das classes dominantes.

Êsse direito não é privado, porém privativo. É exclusivo e inextensível.

A pirâmide social repousa no escravo, produto das lutas entre as tribos, dos resultados aleatórios do choque pela hegemonia sôbre os territórios, das expedições preda- tórias que resultam em conquista de novos limites ao fundo comunal.

O estrangeiro é inimigo e não tem direitos. A fixação da aldeia, agora Cidade, gerou a propriedade privada que é indisponível titularidade da família - nãc do Chefe - como reminiscência da estrutura coletiva.

Si o trabalho forçado é a base das relações econômicas, o cidadão, agora ocioso, orgulha-se das carreiras que lhe são destinadas: a arte da guerra, o desempenho da Política, mais além os vagares da Filosofia e das Artes.

É compreensível no direito familiar, a extrema autoridade do Pater, para quem a mulher, as filhas solteiras, até o filho casado, a nora, a descendência estarão sob um terrível poder de vida e morte. A propriedade fundiária inalienável, só aos poucos liberta-se do fas para o abutendi. Mas, ainda não se transmite por contrato: é o cerimonial das fórmulas, profundo e público, que permite a simulação de renúncia, a disposição pela traditio, a in jure cessio, a mancipatio.

O direito de sucessão serve aos interêsses de perpetuação do nome. A morte do Chefe consubstancia o retôrno da propriedade ao grupo familiar.

Lê-se na Germânia de TÁCITO que as tribos extensas que a compunham desconheceram completamente o direito de testar. Solo Deus fecit heredem...

Êsse direito, na observação correta de BEUDANT, aparece na história dos povos, como um aspecto do direito de dispor e só assim, no 
instante em que a propriedade, perdendo o seu caráter grupal, tornou-se individual, e, portanto, transmissível...

O sacerdócio familiar que é o culto da gens e o princípio econômico da autoridade do Chefe, e, será a razão formal da escolha do sucessor mais apto, capaz de representar os interêsses do grupo.

A obrigação civil que veio do delito e da ordem pública, como o dever de reparar o mal, o dano, o prejuízo, quando evolui para o contrato, - ainda trás, marcantes, as características patriarcais que hoje dizemos "do fio de barba empenhado", pelas solenidades públicas do ajuste, as conseqüências terríveis da sanção, a morte, a escravização do devedor, efeitos penais do inadimplemento.

O comércio com o estrangeiro humanizará êstes costumes - e da gênese criadora do direito pretoriano, surge a extensão do édito, a vulgarização no Império, que - frente aos anseios libertatórios de outros povos conflitantes, se vê na contingência de proclamar uma cidadania universal, como medida política de um retardamento de curta duração...

Não é de modo algum diferente a evolução dos impérios orientais, onde 0 interêsse da classe ditando a lei, traduz-se nas oligarquias conjugadas do poder sacerdotal, do fisco, da administração e da justiça.

A justificação legal difere nas minúcias, mas sempre se apoia no caráter divino da lei revelada, e assim a divisão de castas que é em última análise uma gradação de classes, explica-se no Código de Manu, porque o Brahamane saiu da cabeça de Brahma, o kchatria ou guerreiro de seus braços, o elemento servil ou Sudra de seus pés, revelando daí que a discriminação anatômica, mesmo no corpo de um Deus, pode ter conseqüências políticas, sociais, e sobretudo econômicas...

O Deuteronômio ou Livro dos Juízes, embora proclamando o povo eleito do Senhor, recomendava o respeito ao rei ungido, porque 0 regime popular eleva ao poder os piores cidadãos, eis que os "melhores" desdenham de entrar em competição...

Nas suas regras de discriminação, encontra-se que não se empreste com usura ao próprio irmão, mas que é lícito fazê-lo ao estrangeiro. Ademais proclama a estrutura econômica da escravidão temporária, peculiaridade que serviu a LUIZ DE CAMÕES para o desenvolvimento lírico de um célebre soneto.

A fonte permanente dos escravos é a guerra. Roma, Grécia, os impérios orientais exauriram-se em conquistas. A exploração dos povos importa na destruição das fôrças produtivas. O trabalho do escravo só beneficia a classe dos senhores.

Pelo empobrecimento geral das populações e o declínio do comércio, o trabalho escravo deixa de ser econômicamente sustentável. A decadência das grandes explorações, latifundia, gera o colonato, exploração dos escravos libertos e plebeus que recebem porção de terra para o trato, e com trabalho semi-livre retribuem em espécie. O servo, evidentemente, pertence à terra, não ao senhor, e vende-se com ela. 
Destruído o fundamento de 'sua economia, ruem os impérios do mundo antigo. As revoltas dos escravos, precedem a antítese dos po.vos submetidos. Assim consecutivamente desapareceram uma a uma as hegemonias teocráticas.

Mirando o exemplo ocidental de uma nova estrutura e de novas relações civis, eis que os clans germânicos se assenhorearam do Ocidente. A ocupação das terras pelos chefes militares, mais tarde senhores e barões, cria um novo poder político. O colonato aprofunda-se na relação de produção típica de consumo. O artezão trabalha sob encomenda. Estanques as baronias; agravado o tráfico pelos escorchantes impostos locais do pedágio, passagem; ineficazes as vias de comunicação, resume-se a economia agrária nos interêsses da família aristocrática. Essas relações familiares que se estipulam dentro de classes fechadas, tem profundas raízes na política que resulta da economia feudal. $O$ soberano prefere que o castelo fronteiriço que lhe protege o território seja comandado pelo mais apto e mais experiente. Essa estrutura predomina sôbre a lei romana e até sôbre os costumes, para engendrar um direito hereditário que dá preferência ao herdeiro mais velho, descendente pela linha masculina. O poderio do vassalo, a unidade do comando, a riqueza acumulada em poucas mãos constituem segurança de útil assistência ao suserano, no dizer bem ponderado ao René SAVATIER. A propriedade fundiária constitui o que se chama de bens de raiz ou de legítima.

E axiomático que êsse período trás em si uma apatia ao desen- volvimento de um direito de obrigações.

Mas, nas cidades livres, com exércitos próprios, acrescidas pelo abandono dos campos, agrupam-se as corporações profissionais, empreendem-se as navegações, o comércio, as descobertas, cria-se um capitalismo urbano para cujas necessidades é ineficiente a produção artesanal. Surge um direito mercantil, e eis a letra de câmbio, os estatutos dos mercadores, as normas de transportes, começam as manufaturas fabris, e a livre iniciativa aniquila os monopólios de Estado. É evidentíssimo que êste novo ciclo não pode ser governado pelos princípios econômicos, políticos, jurídicos do feudalismo.

Proclamada a liberdade da pessoa humana, derrubados os privilégios do nascimento, desloca-se o poder político. O liberalismo engendra os seus Códigos: a família constitue-se sob a égide de um contrato bilateral de matrimônio que, em princípio, como todos os contratos pode ser anulado por vício de origem, pode ser rescindido por inadimplemento dos deveres concomitantes. Esta rescisão também pode ser feita por mútuo consentimento e denomina-se divórcio. A propriedade, função da livre circulação de bens, passa a ser objeto de comércio. A sua segurança exige um cadastro imobiliário. A posse, fenômeno nìtidamente econômico, aufere proteção legal mesmo em detrimento da propriedade, apesar dela e contra ela. O direito de sucessão recebe do direito inglês a liberdade de testar, - e a maioria dos países, ressalvando o princípio da conservação econômica da família pela preservação da 
legítima, proclama a faculdade de dispor do excedente.

O direito de obrigações estipula a liberdade contratual, destinandose os Códigos a continentes de regras supletivas, definindo meramente as instituições típicas, regulando as conseqüências da vontade aceita. Libertado o indivíduo da integração absorvente do Estado antigo, os direitos subjetivos são poderes que se concedem ao indivíduo como um meio de satisfação de seus próprios interêsses, - que são quase absolutos quando, por exemplo, se inaugura um direito real, oponível contra todos, sem outras limitações que os direitos semelhantes, fronteiriços, como as relações de vizinhança. São poderes aquêles que, quando se realizam nas relações meramente pessoais, de sujeito, não encontram maiores obstáculos, no regimento legal, senão quanto à forma e aos meios de prova, à licitude e possibilidade do contrato, também as exceções relativas aos vícios de vontade.

Tôda esta estrutura repousa na liberdade civil e na desigualdade social.

É a expressão legal do período de desenvolvimento capitalista, que precisou da concorrência para vencer, mas não prescinde do monopólio para subsistir.

O ilimitado subjetivismo da livre iniciativa gera o poder econômico dos trusts, a exportação de capitais, como as formas econômicas do capitalismo haviam criado um novo regime de produção pela venda da fôrça do trabalho e a conseqüente retenção da plus valia em mãos dos compradores do trabalho. A reação das classes ex- ploradas eclode nos movimentos reivindicatórios, como entre povos, reagem pela sua libertação os mal desenvolvidos, contra a intromissão dos fortes nas diretrizes de sua política - e a impiedosa exploração de suas riquezas naturais. A revolução econômica que se produziu neste século, o entrechoque dos imperialismos antagônicos, irão engendrar novas e profundas modificações. O socialismo inaugura as suas vias de realização. O princípio da igualdade política, preponderante no Estado Liberal, é acrescido da igual oportunidade econômica, para todos. Há um mínimo ditado pela necessidade, um máximo conseguido pela capacidade. É claro que a realização dêsses propósitos implica em eliminar progressivamente as causas de contraste. Segue-se a expropriação da propriedade dos meios de produção. Ao lado da propriedade estatal e da propriedade cooperativa, remanesce a individual, nos edifícios privados, nos instrumentos e meios pessoais, nas pequenas emprêsas, nas coisas de uso doméstico, na economia familiar. Em conseqüência a sucessão, por testamento ou vocação legal, admite-se sôbre êsses bens, mas o direito de dispor causa mortis sofre restrição. Não se distingue entre filhos naturais e legítimos, e o testador que os tenha menores de 18 anos não pode privá-los de sua quota hereditária. Ela consiste em $3 / 4$ do espólio. $\mathrm{O}$ legado pode ser a pessoa que vivesse na dependência econômica do disponente; ou beneficiar o Estado, Organizações e Pessoas Jurídicas, ainda com indicação dos fins de sua aplicação. À falta de disposição, ou de descendentes, defere-se a sucessão ao cônjuge, as- 
cendentes, colaterais de primeiro grau. As disposições especiais sôbre o seguro social garantem a manutenção, dessas pessoas. $O$ direito de família tem um Código especial. A espôsa de fato não precisa fazer prova de dependência para acorrer à sucessão. A declaração do estado de filiação foi sumàriamente simplificada. São rigorosas as disposições sôbre alimentos. Mas o Estado protege a juventude, toma a seu cuidado o filho natural. $O$ estudante de qualquer curso profissional ou superior é considerado um trabalhador e recebe salário de manutenção. Si por um lado, a nacionalização dos bens produtivos parece acarretar uma diminuição do campo incidente no direito de obrigações, êste ganha novo conteúdo e complexa riqueza com o fenômeno da planificação. Os chamados contratos econômicos, estipulados entre as organizações estatais, as cooperativas, as fazendas coletivas, e o próprio Estado, através dos órgãos de planejamento, descentralizam e cumprem as metas de desenvolvimento, dentro da reciprocidade de financiamento, assistência, fornecimento de sementes e matérias primas, com a obrigação indeclinável da produção preordenada, cuja colocação é óbvio está precedentemente assegurada.

Si no contrato econômico é possível a discussão do plano e da tarefa, todavia, estipulado o seu prévio objetivo, há OBRIGATORIEDADE DE CONTRATAR, o que choca o espírito liberal, mas é perfeitamente compreensível nos moldes da estrutura onde, a pessoa jurídica só tem como objetivo e destinação aos de uma unidade responsável dentro do coletivo, que realiza as próprias finalidades sociais.

Por outro lado, o próprio mundo capitalista, dentro das contradições que lhe são inerentes, pelo princípio da competição que o socialismo supera pela cooperação foi obrigado à revisão das teorias liberais que foram a base econômica e filosófica do Código Napoleão.

A concorrência desleal, o desperdício, a ausência de planificação, a nocividade de certos empreendimentos, o caráter supletivo da lei sempre ausente da realidade social, sugeriram a eclosão da teoria do abuso do direito. Tal foi a expressão legal de um intervencionismo de Estado que hoje se intromete nas relações privadas nas quais reconhece implìcitamente um conteúdo de classe e portanto a desigualdade econômica das partes contratantes. O caráter paternalista do Estado vem substituir a regra supletiva pela lei normativa, que restringe a liberdade de contratar, em benefício da parte econômicamente mais débil, como medida de apaziguamento e retardamento nas contradições de classe, e eis todo o conteúdo do direito do Trabalho, o salário mínimo, a jornada de oito horas, as férias, a despedida injusta, a estabilidade, a indenização, onde antes chamava-se a polícia para por o operário na rua. Os contratos civis 'realizam-se sob a fiscalização do Estado, com as normas especiais sôbre garantia de cumprimento, a revisão das prestações imprevistamente onerosas ou impossíveis, a proteção à economia popular, o tabelamento, a obrigação de vender, a repressão à usura, à lesão enorme, às formas de locupletamento 
considerado ilícito face à fraqueza e desigualdade econômica, o desnível social entre as partes contratantes. A economia industrial, a densidade demográfica das cidades comandam certos monopólios de serviços e eis o surgimento dos contratos de adesão. No resguardo de suas riquezas potenciais, o Estado defende-se nacionalizando certos setores da produção, impedindo a sangria financeira da exportação de lucros ou da remessa de matérias fundamentais para o estrangeiro, reprimindo a ação dos trusts, das grandes emprêsas internacionais.

Por outro lado, a propriedade passa a ser função social de sua utilização. Expropria-se o jazimento mineral, o potencial hidráulico, que se desligam da propriedade do solo. Reconhece-se a usocapião breve do não proprietário nas zonas rurais, quando à ocupação prolongada se faz acompanhar de produtividade e fixação. No direito de família, naqueles países onde um funesto preconceito e falsas razões de moralidade confessional ainda mantém a indissolubilidade do vínculo do matrimônio, proclama-se reconhecível o filho do desquitado, declara-se prevalente junto às instituições de previdência social, o direito da companheira, da espôsa de fato, a quem a jurisprudência vencedora dos Tribunais reconhece o direito à participação de um patrimônio comum realizado também com seu esfôrço.

Nos estreitos limites desta aula não posso oferecer-vos mais detalhes, senão êste apanhado panorâmico.

A vida social entrelaça o indi- víduo em grupos e círculos onde se desenvolve a sua atividade. Simultâneamente pertencemos à família, ao sindicato, ao clube, à sociedade comercial. São várias e complexas essas relações que se tornam políticas frente ao organismo maior que é o Estado.

Diante do fenômeno social podemos anotar duas atitudes: a explicativa e a valorativa. Pela primeira entendemos as coisas come são. Pela segunda buscâmo-las como deviam ser. Cada filosofia pretende que seja duradouro - eterno - o seu ideal de convivência, como conveniência dos interêsses de classe que politicamente representa e em cuja economia assenta as suas bases e até a subsistência material de seus filósofos. O espírito humano, na honesta formulação do prof. NELSON DE SOUSA SAMPAIO, pode ser obscurecido e desviado no domínio político, muito mais fàcilmente do que no conhecimento da natureza, pois insensìvelmente recebemos da sociedade um mundo de preconceitos e falsas noções. Todos os detentores do poder timbram em cultivar e difundir as idéias do statu quo que lhes é propício e em exercitar a censura mental, direta ou indireta, sôbre os carneiros pretos que se afastam da passividade do rebanho. Quando ULPIANO, repetindo a velha formulação aristotélica do "hábito ou disposição de realizar o justo", definia a Justiça como a constante e perpétua vontade de dar a cada um o que é seu, - estava sendo injusto porque falsificava a verdade histórica para fabricar um impenitente chavão para o uso entorpecente das veleidades da plebe romana.

Si a Justiça ainda vem de cima, 
como aplicação funcional da lei, é justo que registremos o esfôrço dos bons Juízes que, a cada passo, na consciência de um justo menos formal e mais efetivo, forçam a aplicação dinâmica da lei em têrmos de hermenêutica revolucionária para que se cumpra a sua destinação social. Mas a verdadeira Justiça é a luta pelas suas vias reais de aplicação, inatingível senão quando se muda por outra a lei superada, e essa superação há de se fazer, primeiro, na transformação das condições sociais que ditam e comandam a razão política da lei.

Um grande professor da Universidade de Roma disse, certa feita, que a história que se devia escrever não é dos homens representativos de uma época, mas das verdadeiras razões efetivas e dos interêsses realmente predominantes que ditaram o seu teor. $O$ justo da razão política verificar-se-ia, quase sempre seria contraditório ao justo da necessidade social, e porisso de maior número.

Estudantes e mestres em convívio universitário, fundamentalmente não podemos subestimar a função científica que é primordial em uma Universidade: o exame do fato social em têrmos de ciência não pressupõe apenas a constatação formal das coisas como são, senão como devem ser. Do mesmo modo, nos laboratórios e nos anfiteatros, ninguém se esforça pelo academicismo de dar um nome ao novo fato patológico, ou batizar um mi- cróbio, mas para encontrar a antítese do bacilo ou o remédio que elimine as causas do estado mórbido.

Para libertar o homem não basta "que se varram do seu espírito as trevas seculares da opressão e da ignorância".

Mas a conquista dêsse esclarecimento de espírito em muito contribue para que também se varram as causas da opressão e do obscurantismo.

$O$ homem que se libertou da condição animal pelo trabalho, pode e deve trabalhar pela melhoria progressiva de sua organização social, pelo aperfeiçoamento de suas relações humanas. A ciência política não pode ser dogmática, muito menos emocional...

Ninguém pretende o milagre das superações instantâneas, nem o gesto heróico do esfôrço de um minuto. Mas, a continuidade de um trabalho paciente e duradouro para que o homem e a sociedade dos homens sejam melhores e felizes.

Disse RUI que nem tôda a ira é maldade. Porque aquêle que braveja pelo bem, não sòmente não peca se houver ira, mas pecará não se irando.

Permiti que termine com o magno Tribuno: O trabalho pois, vos há de bater à porta dia e noite; e nunca vos negueis às suas visitas se quereis honrar a vossa vocação. 